\title{
Ivabradine-The Final Crusader for Postoperative Junctional Ectopic Tachycardia, a Case Report with Literature Review
}

\author{
Manoj Kumar Sahu*, Harsha Vardhan Niraghatam, Nikhil Bansal, Sarvesh Pal Singh, \\ Palleti Rajashekar, Shiv Kumar Choudhary \\ Department of Cardiothoracic and Vascular Surgery, CN Centre, All India Institute of Medical Sciences, New Delhi, India \\ Email: *drmanojsahu@gmail.com
}

How to cite this paper: Sahu, M.K., Niraghatam, H.V., Bansal, N., Singh, S.P., Rajashekar, P. and Choudhary, S.K. (2019) Ivabradine-The Final Crusader for Postoperative Junctional Ectopic Tachycardia,

a Case Report with Literature Review. World Journal of Cardiovascular Surgery, 9, 73-82.

https://doi.org/10.4236/wjcs.2019.98009

Received: June 24, 2019

Accepted: August 19, 2019

Published: August 22, 2019

Copyright $\odot 2019$ by author(s) and Scientific Research Publishing Inc. This work is licensed under the Creative Commons Attribution International License (CC BY 4.0).

http://creativecommons.org/licenses/by/4.0/

\section{(c) (i) Open Access}

\begin{abstract}
Background: Junctional ectopic tachycardia (JET) is one troublesome supraventricular arrhythmia in postoperative pediatric cardiac surgical patients. Unless treated timely and effectively it may lead to morbidity and even mortality. Aim: To understand the role of Ivabradine in the treatment of JET in postoperative pediatric cardiac surgical patients. Case: We present a postoperative case of complete repair of Tetralogy of Fallot who was in normal sinus rhythm in the preoperative period and developed JET 4 hours later in postoperative period which was persistent despite measures to optimize the internal milieu of the body and conventional antiarrhythmics, that was successfully treated with Ivabradine at a dose of $0.05 \mathrm{mg} / \mathrm{kg} / 12$ hourly. Conclusion: Ivabradine can be used to successfully treat postoperative JET in cases of refractory to other antiarrhythmic drugs like Digoxin and Amiodarone.
\end{abstract}

\section{Keywords}

Tetralogy of Fallot, Junctional Ectopic Tachycardia, Ivabradine

\section{Introduction}

Junctional ectopic tachycardia (JET) is the commonest rhythm disturbance following surgery for congenital heart disease [1] and is usually self-limiting [2]. Control of heart rate or conversion to sinus rhythm is of paramount importance but is often challenging and may require more than one antiarrhythmic drug for its treatment [3] [4]. JET focus ablation or atrioventricular (AV) node ablation along with permanent pacemaker implantation (PPI) has been reported but with a significant risk of AV node block [3]. 
Ivabradine is a new rate-controlling drug used as a selective antagonist of the $\mathrm{I}_{f}$ current and produces substantial reduction in the rate of spontaneous action potential firing in sinoatrial node cells [5] (at concentrations that have no effect on other ionic currents, in particular $\mathrm{T}$ and $\mathrm{L}$ type calcium currents and delayed-rectifier potassium current).

We sought to assess if ivabradine could successfully control heart rate in a child with refractory JET. The successful treatment of our patient with oral ivabradine provides a new therapeutic option, having its action on AV node along with SA node, its uncommon use in postoperative pediatric cardiac surgical patients without any side effects.

\section{Case Report}

A14 year old girl weighing $38 \mathrm{~kg}$ diagnosed with Tetralogy of Fallot (TOF) with Normal Sinus Rhythm (NSR) (Figure 1) underwent intracardiac repair. Ventricular septal defect was closed using dacron patch, infundibular resection was performed and trans annular patch repair was done with autologous pericardium. She was received in the intensive care unit (ICU) with dobutamine 5 $\mathrm{mcg} / \mathrm{kg} / \mathrm{min}$ and sodium nitroprusside $0.5 \mathrm{mcg} / \mathrm{kg} / \mathrm{min}$ with stable hemodynamics. After 4 hours she developed JET with a heart rate of 150 beats/min (Figure 2). She was afebrile, her blood pressure remained normal, she did not show any sign of low cardiac output (LCO) and her serum potassium was at 3.3 meq/L. Transthoracic echocardiography (TTE) revealed moderate right ventricular (RV) dysfunction, no residual VSD, no gradient across RV outflow tract, no tricuspid regurgitation, mild pulmonary regurgitation and normal left ventricular contractility. Dobutamine dose was increased to $10 \mathrm{mcg} / \mathrm{kg} / \mathrm{min}$. Serum potassium and hypovolemia were corrected and magnesium sulfate $20 \mathrm{mg} / \mathrm{kg}$

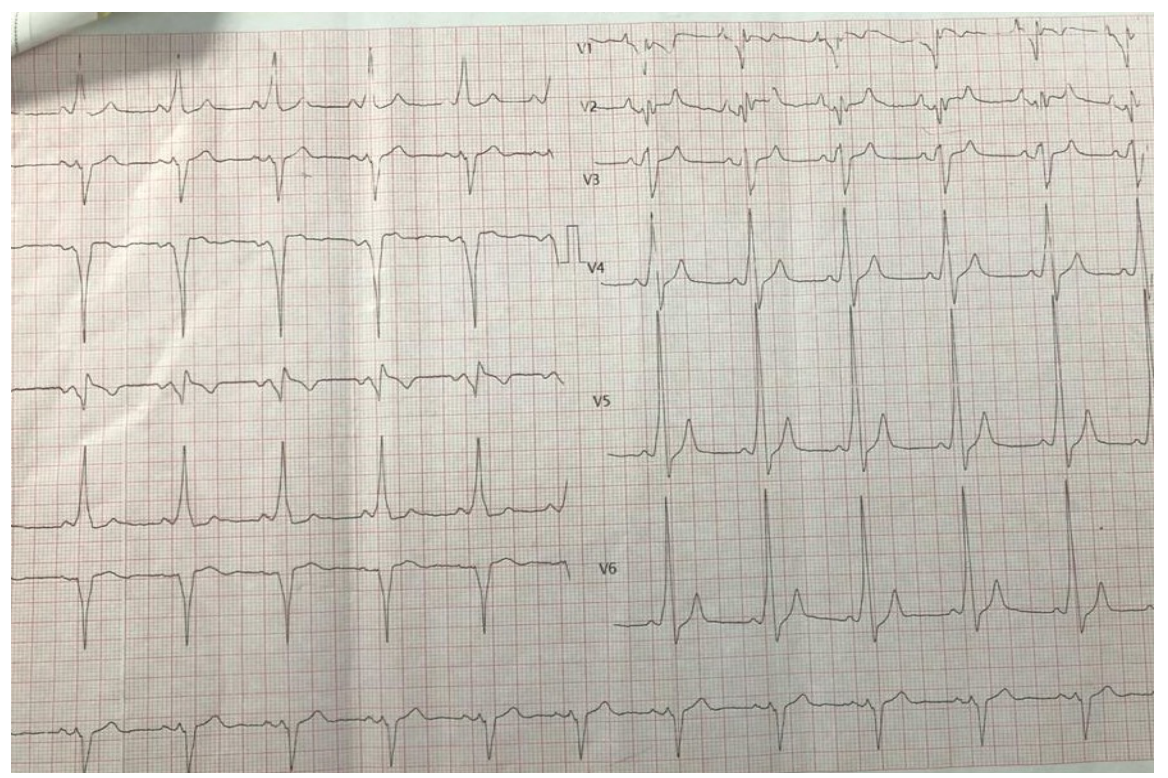

Figure 1. Preoperative electrocardiogram showing normal sinus rhythm. 


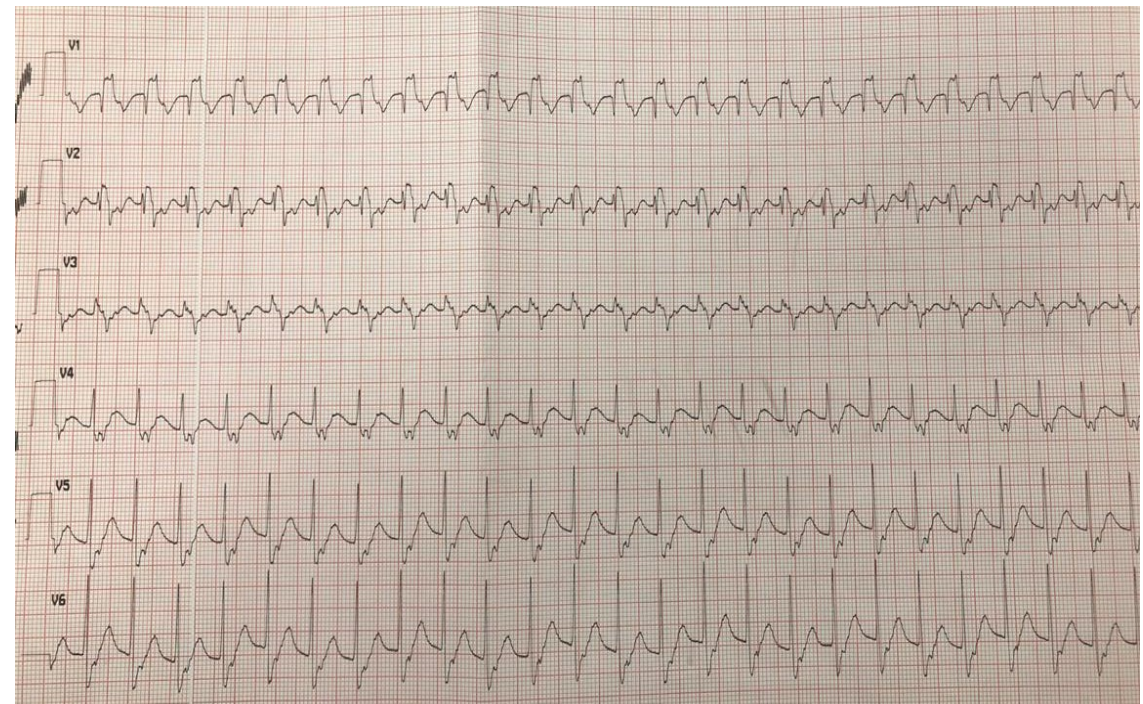

Figure 2. Postoperative electrocardiogram showing Junctional Ectopic Tachycardia.

slow iv bolus was given over 20 minutes. But JET continued at a rate of 150 $170 / \mathrm{min}$. Intravenous digoxin was given at $5 \mathrm{mcg} / \mathrm{kg}$ slow iv bolus and repeated twice at two hourly intervals as per our ICU protocol. When digoxin after 3 doses was unable to control the heart rate, amiodarone was administered as $5 \mathrm{mg} / \mathrm{kg}$ as slow iv bolus followed by infusion at a rate of $10 \mathrm{mcg} / \mathrm{kg} / \mathrm{min}$. Amiodarone infusion for 24 hours did not able to settle either rhythm or tachycardia. Hence ivabradine was given enterally through nasogastric tube at a dose of 0.05 $\mathrm{mg} / \mathrm{kg} / 12$ hourly. About three hours after the $1^{\text {st }}$ dose, heart rate dropped to 80 beats/min and the rhythm of JET reverted back to normal sinus rhythm (NSR) (Figure 3). Ivabradine was continued at a dose of $2 \mathrm{mg}$ twice daily. The hemodynamic parameters remained stable and further TTE after 24 hours of NSR showed normal biventricular function and the child was weaned off the ventilator. The inotropes were tapered gradually from postoperative day 2 and the child was discharged from ICU with ivabradine $2 \mathrm{mg}$, furosemide $10 \mathrm{mg}$ and enalapril $1.25 \mathrm{mg} /$ orally/twice daily. There was no reversal to JET rhythm in follow up electrocardiogram (ECG) monitoring during the hospital stay, and the child was discharged home with NSR on $12^{\text {th }}$ POD.

\section{Discussion}

JET is a common postoperative rhythm disturbance in patients of TOF repair [1] and is usually self-limiting [2]. The mechanism of the JET is thought to be abnormal automaticity arising from the region of the atrioventricular junction. Excessive traction on the conduction bundle near the AV node during surgery is responsible for postoperative JET. Risk factors such as dyselectrolytemia, hyperthermia, prolonged cardiopulmonary bypass $(\mathrm{CPB})$ time, and high inotropic score also contribute to postoperative JET [1] [6]-[11]. Borgman KY et al. identified that postoperative JET is also caused due to angiotensin-converting enzyme insertion/deletion polymorphism [12]. These infants had a higher risk for 


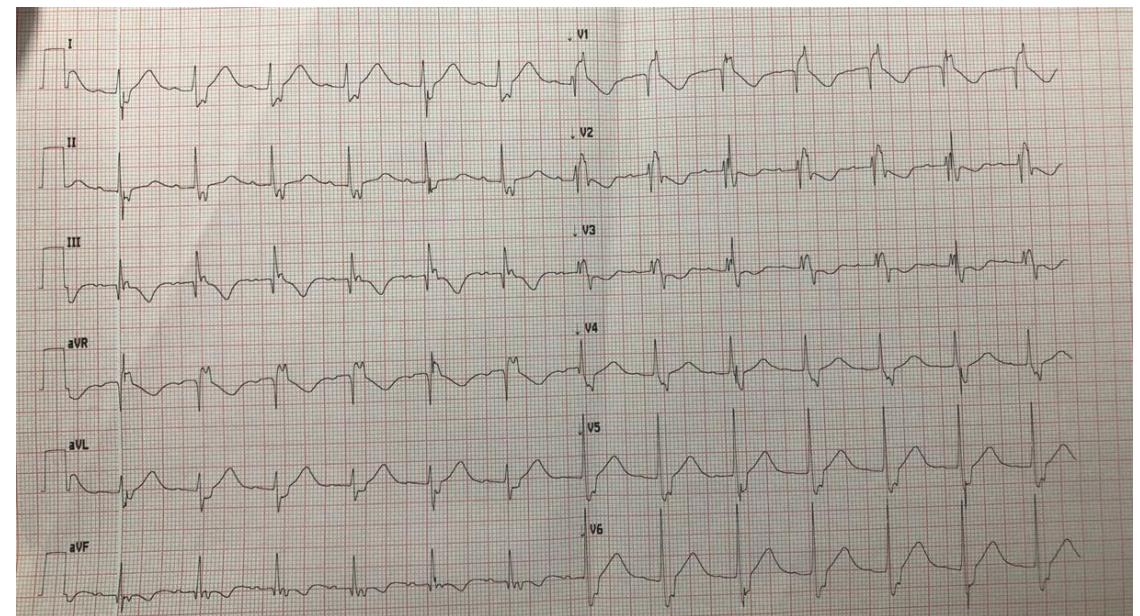

Figure 3. Elctrocardiogram showing revertion of Junctional Ectopic Tachycardia back to normal sinus rhythm after oral Ivabradine therapy.

incessant tachycardia and a fatal outcome [3]. Tachyarrhythmia leading to myocardial dysfunction and vice versa is true in these scenarios. So control of heart rate and reverting to sinus rhythm are of paramount importance, often challenging and require more than one antiarrhythmic drug, with amiodarone being used most frequently [3] [4]. A combination of medical therapy and electrophysiological study aiming for JET focus elimination by atrioventricular nodal ablation and PPI has been reported in resistant cases [3]. However, the risk of AV block is significant, with studies reporting the incidence as high as $18 \%$ [3]. Although the management of JET has improved in recent years, it remains a significant challenge, particularly in younger patients.

Our patient underwent intracardiac repair for TOF. She developed JET in the ICU, which could be attributable to a major infundibular resection and postoperative moderate RV dysfunction as demonstrated by echocardiography. This JET was persistent despite the routine measures to normalize the internal biochemical milieu and treatment with regular antiarrhythmics like digoxin and amiodarone as per our ICU protocol. And also we stepped up the dobutamine infusion to support the RV, but when all these measures failed to control JET, we started Ivabradine enterally and dramatically the rate and rhythm came under control after the $1^{\text {st }}$ dose and then RV function improved by next TTE.

There are several mechanisms by which a low or reduced heart rate could be of benefit. Myocardial ischemia occurs when coronary perfusion is insufficient to satisfy myocardial oxygen demand and heart rate is an important determinant of myocardial oxygen demand. A reduction in heart rate will increase the duration of diastole relative to cardiac cycle length, thus allowing more time for effective left ventricular perfusion. In this way, a reduction in heart rate should improve both aspects of myocardial oxygen balance.

Therefore, drugs that reduce heart rate should be of benefit in the postoperative tachyarrhythmia situations. However, current heart rate-reducing drugs like amiodarone, digoxin, etc. are non-specific and have actions on the cardiovascu- 
lar and other systems, which both complicate the interpretation of the effects of heart rate lowering, and may be harmful. More specific heart rate lowering agents without having many side effects and drug interactions could, therefore, be of interest.

Ivabradine is a new, pure rate-lowering drug that acts by inhibiting the cardiac pacemaker $\mathrm{I}_{f}$ (funny) current channels underlying the normal pacemaker function of the sinus node [13]. These pacemaker currents are also present in the AV node and His-Purkinje cells of the cardiac conduction system, as well as in immature ventricular myocardium. $\mathrm{I}_{f}$ current is a sodium-potassium inward current, and flows through channels made up of tetramers of hyperpolarization-activated cyclic nucleotide ( $\mathrm{HCN}$ ) channel proteins causing depolarization of myocardium during diastole as a result of which spontaneous activity in sinoatrial myocytes is reduced [14] [15] [16]. Four distinct isoforms of these channel proteins have been cloned, with HCN4 being the predominant isoform in the sinus node. A related channel, HCN3 has increased expression in the AV node (5.5 fold greater than ventricular myocardium) based on a mouse reporter gene model [17]. Ivabradine acts within the pore of the channel, entering from the cytoplasmic side when the channel is open, and thus demonstrating use dependence.

Ivabradine was approved by the European Medicines Agency in 2005. Ivabradine has been used in adult patients to reduce the heart rate alone in sinus tachycardia in the treatment of stable angina and heart failure [18] [19] [20] [21] [22] [23]. Ivabradine also decreases the ventricular rate in patients with atrial fibrillation by means of rate dependent slowing of conduction without causing myocardial depression [24]. Verrier RL et al. proposed ventricular rate control in patients with atrial fibrillation without myocardial depression when Ivabradine and Ranolazine were used combinedly [25]. Bohora S et al. reported to successfully treat a focal left atrial tachycardia using ivabradine in a dose of $2.5 \mathrm{mg}$ twice daily in a 15-year-old child [26].

In a randomized controlled trial by Nguyen LS et al. on 19 postoperative coronary artery bypass graft surgery patients with LCO with dobutamine induced sinus tachycardia, intravenous ivabradine administered as loading dose of $10 \mathrm{mg}$ over $10 \mathrm{~min}$, followed by $10 \mathrm{mg}$ over 24 hours lead to effective control of heart rate, stroke volume and cardiac index [27]. Al-Ghamdi S et al. reported successful treatment of congenital JET in a 2 years old child using ivabradine at a dose of $2.5 \mathrm{mg}$ once daily [28]. Dieks JK et al. proposed a protocol for the successful treatment of congenital JET in 5 patients using ivabradine as an additional drug in a mean dosage of $0.22 \mathrm{mg} / \mathrm{kg} /$ day along with amiodarone, propranolol, flecainide and digoxin [29]. Kumar V et al. reported a successful reversal of postoperative refractory JET to normal sinus rhythm in 2 postoperative congenital cardiac surgical patients treated with ivabradine at a dose of $0.1 \mathrm{mg} / \mathrm{kg} /$ day twice daily [30].

In an uncontrolled study in 14 patients needing cardiac electrophysiological investigation or catheter radiofrequency ablation for supraventricular arrhyth- 
mia, but with normal electrophysiology at study baseline, a single intravenous administration of ivabradine $(0.2 \mathrm{mg} / \mathrm{kg}$ corresponding to approximately $10 \mathrm{mg}$ twice daily orally) reduced resting heart rate by approximately $14 \mathrm{bpm}$, but did not induce any change in major electrophysiological parameters other than those related to heart rate [31].

In a randomized, placebo-controlled study in 44 patients with left ventricular dysfunction, a single intravenous infusion of ivabradine $0.2-0.3 \mathrm{mg} / \mathrm{kg}$ reduced resting heart rate by over $17 \%$, but did not alter left ventricular ejection fraction, fractional shortening or stroke volume as determined by echocardiography [32]. The absence of effects on myocardial contractility and cardiac electrophysiology is attributable to the lack of effect of ivabradine on cardiac ion currents other than the $\mathrm{I}_{f}$ and demonstrate that pure heart rate lowering can be achieved as a result of specific and selective $\mathrm{I}_{f}$ current inhibition.

According to the electrophysiologic properties of ivabradine, the purpose of reporting this case review was to assess the efficacy and safety of ivabradine as an adjunctive agent in treating postoperative JET in children. Because pharmacologic treatment with various antiarrhythmic medications often fail to treat JET effectively, timely and catheter ablation carries a high risk of AV block, we used ivabradine as a novel adjunctive therapy to treat junctional tachyarrhythmias in post cardiac surgery children. Adding ivabradine to a combination of antiarrhythmic agents in our patient resulted in conversion to sinus rhythm.

Our protocol for treating JET in postoperative pediatric cardiac surgery is:

1) Controlling the core temperature to normal in case of fever (due to post CPB inflammation, LCO or infection).

2) Correcting serum electrolytes, particularly potassium and supplementing magnesium (to prevent subclinical hypomagnesemia).

3) Treating myocardial dysfunction/heart failure/LCO with the use of inotropes and inodilators at judicious doses while maintaining the mean arterial pressures appropriate for the age.

4) Maintaining euvolemic status (preload) of the patient.

5) Then digoxin for rate control, at a dose of $5 \mathrm{mcg} / \mathrm{kg} / \mathrm{min}$ as slow infusion over 30 min followed by 2 more doses at 2 hourly intervals.

6) If the rate is not controlled by digoxin, we use amiodarone at a dose of 5 $\mathrm{mcg} / \mathrm{kg} / \mathrm{slow}$ iv bolus over 20 minutes and followed by $10 \mathrm{mcg} / \mathrm{kg} / \mathrm{min}$ infusion for 24 hours postoperatively.

7) Recently we started using ivabradine in those children who become refractory to the other drugs and measures, with good success and quicker control of heart rate and rhythm.

Safety of Ivabradine:

As per SHIFT trial, both oral and intravenous ivabradine administration are associated with the incidence of supraventricular arrhythmias and also bradyarrhythmias that respond to standard antiarrhythmic measures and stopping ivabradine [33]. 


\section{Conclusion}

Ivabradine was a new addition to the antiarrhythmic drugs armamentarium in treating junctional tachyarrhythmias postoperatively in children undergoing intracardiac repair. Because ivabradine is a selective $\mathrm{I}_{f}$ inhibitor, one may infer that it is a more targeted therapy than the multichannel blocker amiodarone. However, there is no scientific evidence for this assumption, so a randomized trial is necessary to quantify and compare the efficacy of these drugs for the treatment of this specific arrhythmia. It would be worthwhile to determine whether ivabradine could potentially be the preferred first-line therapy in children with postoperative JET. RCT needs to be done in a large study population.

\section{Consent}

An informed consent was obtained from the child's parents for publication of this case report.

\section{Conflicts of Interest}

We the authors declare that there is no conflict of interest among the authors in writing this manuscript.

\section{References}

[1] Mildh, L., Hiippala, A., Rautiainen, P., Pettila, V., Sairanen, H. and Happonen, J.M. (2011) Junctional Ectopic Tachycardia after Surgery for Congenital Heart Disease: Incidence, Risk Factors and Outcome. European Journal of Cardio-Thoracic Surgery, 39, 75-80. https://doi.org/10.1016/j.ejcts.2010.04.002

[2] Cools, E. and Missant, C. (2014) Junctional Ectopic Tachycardia after Congenital Heart Surgery. Acta Anaesthesiologica Belgica, 65, 1-8.

[3] Collins, K.K., Van Hare, G.F., Kertesz, N.J., Law, I.H., Bar-Cohen, Y., Dubin, A.M., et al. (2009) Pediatric Nonpost-Operative Junctional Ectopic Tachycardia Medical Management and Interventional Therapies. Journal of the American College of Cardiology, 53, 690-697. https://doi.org/10.1016/j.jacc.2008.11.019

[4] Villain, E., Vetter, V.L., Garcia, J.M., Herre, J., Cifarelli, A. and Garson Jr., A. (1990) Evolving Concepts in the Management of Congenital Junctional Ectopic Tachycardia. A Multicenter Study. Circulation, 81, 1544-1549.

https://doi.org/10.1161/01.CIR.81.5.1544

[5] Bois, P., Bescond, J., Renaudon, B. and Lenfant, J. (1996) Mode of Action of Bradycardic Agent, S 16257, on Ionic Currents of Rabbit Sinoatrial Node Cells. British Journal of Pharmacology, 118, 1051-1057. https://doi.org/10.1111/j.1476-5381.1996.tb15505.x

[6] Batra, A.S., Chun, D.S., Johnson, T.R., Msaldonado, E.M., Kashyap, B.A., Malers, J., et al. (2006) A Prospective Analysis of the Incidence and Risk Factors Associated with Junctional Ectopic Tachycardia Following Surgery for Congenital Heart Disease. Pediatric Cardiology, 27, 51-55. https://doi.org/10.1007/s00246-005-0992-6

[7] Andreasen, J.B., Johnsen, S.P. and Ravn, H.B. (2008) Junctional Ectopic Tachycardia after Surgery for Congenital Heart Disease in Children. Intensive Care Medicine, 34, 895-902. https://doi.org/10.1007/s00134-007-0987-2 
[8] Grosse-Wortmann, L., Kreitz, S., Kreitz, R.G., Vazquez-Jimenez, J.F., Messmer, B.J., von Bernuth, G., et al. (2010) Prevalence of and Risk Factors for Perioperative Arrhythmias in Neonates and Children after Cardiopulmonary Bypass: Continuous Holter Monitoring before and for Three Days after Surgery. Journal of Cardiothoracic Surgery, 5, Article No. 85. https://doi.org/10.1186/1749-8090-5-85

[9] Gebauer, R.A., Paech, C., Kolterer, B., Daehnert, I. and Kostelka, M. (2011) Postoperative Junctional Ectopic Tachycardia. Clinical Research in Cardiology, 100, 857-858.

[10] Smith, A.H., Owen, J., Borgman, K.Y., Fish, F.A. and Kannankeril, P.J. (2011) Relation of Milrinone after Surgery for Congenital Heart Disease to Significant Postoperative Tachyarrhythmias. The American Journal of Cardiology, 108, 1620-1604. https://doi.org/10.1016/j.amjcard.2011.07.023

[11] Abelaziz, O. and Deraz, S. (2014) Anticipation and Management of Junctional Ectopic Tachycardia in Postoperative Cardiac Surgery: Single Center Experience with High Incidence. Annals of Pediatric Cardiology, 7, 19-24.

https://doi.org/10.4103/0974-2069.126543

[12] Borgman, K.Y., Smith, A.H., Owen, J.P., Fish, F.A. and Kannankeril, P.J. (2011) A genetic Contribution to Risk for Postoperative Junctional Ectopic Tachycardia in Children Undergoing Surgery for Congenital Heart Disease. Heart Rhythm, 8, 1900-1904. https://doi.org/10.1016/j.hrthm.2011.06.033

[13] DiFrancesco, D. and Camm, J.A. (2004) Heart Rate Lowering by Specific and Selective $\mathrm{I}_{f}$ Current Inhibition with Ivabradine: A New Therapeutic Perspective in Cardiovascular Disease. Drugs, 64, 1757-1765. https://doi.org/10.2165/00003495-200464160-00003

[14] Biel, M., Wahl-Schott, C., Michalakis, S. and Zong, X. (2009) HyperpolarizationActivated Cation Channels: from Genes to Function. Physiological Reviews, 89, 847-885. https://doi.org/10.1152/physrev.00029.2008

[15] Shi, W.-S., Wymore, R., Yu, H.-G., Wu, J.-Y., Wymore, R.T., Pan, Z.-M., et al. (1999) Distribution and Prevalence of Hyperpolarization-Activated Cation Channel (HCN) mRNA Expression in Cardiac Tissues. Circulation Research, 85, e1-e6. https://doi.org/10.1161/01.RES.85.1.e1

[16] Liu, J., Noble, P.J., Xiao, G.-S., Abdelrahman, M., Dobrzynski, H., Boyett, M.R., et al. (2008) Role of Pace Making Current in Cardiac Nodes: Insights from a Comparative Study of Sinoatrial Node and Atrioventricular Node. Progress in Biophysics and Molecular Biology, 96, 294-304. https://doi.org/10.1016/j.pbiomolbio.2007.07.009

[17] Horsthuis, T., Buermans, H.P., Brons, J.F., Verkerk, A.O., Bakker, M.L., Wakker, V., et al. (2009) Gene Expression Profiling of the Forming Atrioventricular Node Using a Novel Tbx3-Based Node-Specific Transgenic Reporter. Circulation Research, 105, 61-69. https://doi.org/10.1161/CIRCRESAHA.108.192443

[18] Andrikopoulos, G., Dasopoulou, C., Sakellariou, D., Tzeis, S., Koulouris, S., Kranidis, A., et al. (2006) Ivabradine: A Selective $\mathrm{I}_{f}$ Current Inhibitor in the Treatment of Stable Angina. Recent Patents on Cardiovascular Drug Discovery, 1, 277-282.

[19] Guglin, M. (2012) Heart Rate Reduction in Heart Failure: Ivabradine or Beta Blockers? Heart Failure Reviews, 18, 517-528. https://doi.org/10.1007/s10741-012-9347-6

[20] McMurray, J.J., Adamopoulos, S., Anker, S.D., Auricchilo, A., Bohm, M., Dickstein, K., et al. (2012) ESC Guidelines for the Diagnosis and Treatment of Acute and Chronic Heart Failure 2012: The Task Force for the Diagnosis and Treatment of Acute and Chronic Heart Failure 2012 of the European Society of Cardiology. De- 
veloped in Collaboration with the Heart Failure Association (HFA) of the ESC. European Journal of Heart Failure, 14, 803-869.

[21] Traynor, K. (2015) Ivabradine Approved for Stable Chronic Heart Failure. American Journal of Health-System Pharmacy, 72, 896.

https://doi.org/10.2146/news150037

[22] Task Force Members, Montalescot, G., Sechtem, U., Achenbach, S., Andreotti, F., Arden, C., Budaj, A., et al. (2013) 2013 ESC Guidelines on the Management of Stable Coronary Artery Disease: The Task Force on the Management of stable Coronary Artery Disease of the European Society of Cardiology. European Heart Journal, 34, 2949-3003. https://doi.org/10.1093/eurheartj/eht296

[23] Benezet-Mazuecos, J., Rubio, J.M., Farre, J., Quinones, M.A., Sanchez-Borque, P. and Macia, E. (2013) Long-Term Outcomes of Ivabradine in Inappropriate Sinus Tachycardia Patients: Appropriate Efficacy or Inappropriate Patients. Pacing and Clinical Electrophysiology, 36, 830-836. https://doi.org/10.1111/pace.12118

[24] Verrier, R.L., Bonatti, R., Silva, A.F., Batatinha, J.A., Nearing, B.D., Liu, G., et al. (2014) $\mathrm{I}_{f}$ Inhibition in the Atrioventricular Node by Ivabradine Causes Rate-Dependent Slowing of Conduction and Reduces Ventricular Rate during Atrial Fibrillation. Heart Rhythm, 11, 2288-2296.

[25] Verrier, R.L., Silva, A.F., Bonatti, R., Batatinha, J.A., Nearing, B.D., Liu, G., et al. (2015) Combined Actions of Ivabradine and Ranolazine Reduce Ventricular Rate during Atrial Fibrillation. Journal of Cardiovascular Electrophysiology, 26, 329-335. https://doi.org/10.1111/jce.12569

[26] Bohora, S., Lokhandwala, Y., Parekh, P. and Vasavda, A. (2011) Reversal of Tachy cardiomyopathy Due to Left Atrial Tachycardia by Ivabradine. Journal of Cardiovascular Electrophysiology, 22, 340-342.

https://doi.org/10.1111/j.1540-8167.2010.01860.x

[27] Nguyen, L.S., Squara, P., Amour, J., Carbognani, D., Bouabdallah, K., Thierry, S., et al. (2018) Intravenous Ivabradine versus Placebo in Patients with Low Cardiac Output Syndrome Treated by Dobutamine after Elective Coronary Artery Bypass Surgery: A Phase 2 Exploratory Randomized Controlled Trial. Critical Care, 22, 193. https://doi.org/10.1186/s13054-018-2124-8

[28] Al-Ghamdi, S., Al-Fayyadh, M.I. and Hamilton, R.M. (2013) Potential New Indication for Ivabradine: Treatment of a Patient with Congenital Junctional Ectopic Tachycardia. Journal of Cardiovascular Electrophysiology, 24, 822-824. https://doi.org/10.1111/jce.12081

[29] Dieks, J.K., Klehs, S., Müller, M.J., Paul, T. and Krause, U. (2016) Adjunctive Ivabradine in Combination with Amiodarone: A Novel Therapy for Pediatric Congenital Junctional Ectopic Tachycardia. Heart Rhythm, 13, 1297-1302. https://doi.org/10.1016/j.hrthm.2016.03.015

[30] Kumar, V., Kumar, G., Joshi, S. and Sharma, V. (2017) Ivabradine for Junctional Ectopic Tachycardia in Post Congenital Heart Surgery. Indian Heart Journal, 69, 666-667. https://doi.org/10.1016/j.ihj.2017.09.007

[31] Camm, A.J. and Lau, C.P. (2003) Electrophysiological Effects of a Single Intravenous Administration of Ivabradine (S 16257) in Adult Patients with Normal Baseline Electrophysiology. Drugs in $R \& D, 4,83-89$. https://doi.org/10.2165/00126839-200304020-00001

[32] Manz, M., Reuter, M., Lauck, G., Omran, H. and Jung, W. (2003) A Single Intravenous Dose of Ivabradine, a Novel $\mathrm{I}_{f}$ Inhibitor, Lowers Heart Rate but Does not Depress Left Ventricular Function in Patients with Left Ventricular Dysfunction. 
Cardiology, 100, 149-155. https://doi.org/10.1159/000073933

[33] Swedberg, K., Komajda, M., Böhm, M., Borer, J.S., Ford, I., Dubost-Brama, A., et al. (2010) Ivabradine and Outcomes in Chronic Heart Failure (SHIFT): A Randomised Placebo-Controlled Study. The Lancet, 376, 875-885.

https://doi.org/10.1016/S0140-6736(10)61198-1 